\title{
Brachial Plexopathy, CTCAE 5.0
}

National Cancer Institute

\section{Source}

National Cancer Institute. Brachial Plexopathy, CT CAE 5.0. NCI Thesaurus. Code C146754.

A disorder characterized by regional paresthesia of the brachial plexus, marked discomfort and muscle weakness, and limited movement in the arm or hand. 